This is a self-archived version of an original article. This version may differ from the original in pagination and typographic details.

Author(s): Budhathoki, Roshan; Väisänen, Ari

Title: Removal of silicon from CFB-derived fly ash leachate in the context of phosphorus recovery

Year: 2018

Version: Accepted version (Final draft)

Copyright: (c) 2018 Elsevier B.V.

Rights: $C C B Y-N C-N D 4.0$

Rights url: https://creativecommons.org/licenses/by-nc-nd/4.0/

Please cite the original version:

Budhathoki, R., \& Väisänen, A. (2018). Removal of silicon from CFB-derived fly ash leachate in the context of phosphorus recovery. Hydrometallurgy, 179, 215-221.

https://doi.org/10.1016/j.hydromet.2018.06.007 


\title{
Removal of silicon from CFB-derived fly ash leachate in the context of phosphorus recovery
}

\author{
Roshan Budhathoki*, Ari Väisänen \\ Department of Chemistry, Renewable Natural Resources and Chemistry of Living \\ Environment, University of Jyväskylä, P.O. Box 35, FI-40014 Jyväskylä, Finland
}

\begin{abstract}
High concentrations of dissolved silica in the acid leachate impose two major challenges on precipitation based recovery of phosphorus (P). Firstly, coprecipitation of colloidal silica in the acidic regimes decreases the purity and value of precipitated P-products. In addition, silica scaling on internal surfaces of equipment is also a problematic issue in industrial operations. Therefore, removal of dissolved silica prior to P-recovery process minimizes the risks of Sicontamination in P-products and Si-scaling. In the present study, silica removal was achieved by accelerated silica polymerization with higher acidity and ionic strength of mineral acid, which also assisted the leaching of CFB-derived fly ash, by aging of the leachate solution. The effects of acid concentration, temperature, and stirring on silica removal rate in acid leachate were also investigated. Higher concentrations of $\mathrm{H}^{+}$and $\mathrm{Cl}^{-}$and higher temperature significantly reduce the silica removal time. $\mathrm{HCl}$ was more suitable for improving leachability of phosphorous and precipitating silica in comparison with $\mathrm{HNO}_{3}$. The silica removal method discussed in this work has been shown to be capable of removing more than $98 \%$ of dissolved silica from the acid leachate solution.
\end{abstract}

Keywords: Phosphorus recycle, Silica removal, Silica polymerization, Fly ash utilization

\footnotetext{
* Corresponding author

Email address: roshan.budhathoki@jyu.fi (Roshan Budhathoki)
} 


\section{Introduction}

Phosphorus, being a limited and depleting element, has a large anthropogenic footprint. Production of phosphorus-containing products highly depends on apatite minerals as raw materials [1]. As an alternative to natural resources, phosphorous can be recycled from waste-to-energy products, such as municipal solid waste incineration fly ash [2], chicken manure incineration ash [3], sewage sludge ash [4], etc. using hydrometallurgical methods (acid leaching). Depending on temperature and combustion technology, the residual inorganic ash is composed of silicates, oxides, carbonates, phosphates, sulphates, hydroxides, and halides of mineral elements that potentially represent the entire periodic table $[5,6]$. In recent years, circulating fluidized bed (CFB) boilers have attracted attention in combustion technology due to their high efficiency, fuel flexibility and low pollutant emission $[7,8]$. Due to the usage of silica sand in the $\mathrm{CFB}$ combustion of biomass as fuel, silicon $(\mathrm{Si})$ can be retained in the fly ash [9] up to $20 w \%$ [10, 11]. Phosphorus recovery from ash residues involves chemical leaching which extracts phosphorus from solid to aqueous phase along with various impurities, including silicon as a major contaminant.

Silica scaling is one of the most problematic issues in many industrial operations. It occurs when Si concentration increases above the saturation level at a given temperature and $\mathrm{pH}$ in the presence of other metal ions and is extremely difficult and costly to remove [12]. Whilst the effect of silica on phosphorus precipitation in acidic solutions has not yet been investigated, the inhibiting effect of silicic acid on the precipitation of $\mathrm{CaCO}_{3}$ and co-precipitation of silica with iron during Zn recovery have been reported [13, 14]. Silica precipitation as amorphous or colloidal silica in both acidic and basic solutions via polymerization, agglomeration and aggregation possesses a great threat to the purity of any product being recovered. Therefore, the removal of silica from the feed solution improves the product quality and the economy of the overall operation. Soluble and colloidal silica have been successfully removed from industrial feeds by a number of different methods including coagulation, nano-filtration (NF), 
reverse osmosis (RO), precipitation of Si particles, precipitation with polyvalent metal hydroxides, lime-soda softening, seeding or inorganic ion-exchange $[15,16,17,18,19]$. A major limitation of coagulation is that it mostly occurs at high $\mathrm{pH}$ and requires high dosages of the coagulants and flocculants [15, 20]. Drawbacks of NF and RO processes are associated with fouling problems and high energy consumption [21]. Numerous studies have reported the precipitation of Si particles in acidic solutions in the context of Si-gel formation and its characterization $[13,22,23,24]$. These studies also emphasize that Si-gel precipitation is accelerated by $\mathrm{H}^{+}$ions (as indicated by $\left.\mathrm{pH}\right)$, salt $\left(\mathrm{AlCl}_{3}, \mathrm{CaCl}_{2}\right.$, $\mathrm{NaCl}$ ) concentration, ionic strength of the solution and temperature.

In an effort to develop simple, low-cost and efficient silica removal methods from highly acidic CFB-derived fly ash leachate solution, this study mainly explores the effect of acid concentration and temperature on the feasibility and rate of silica removal prior to phosphorus recovery via precipitation. One of the primary objectives in this study was to avoid contamination and complexity during phosphorus recovery. Hence, the addition of coagulants or other antiscalant products, which promote coagulation and aggregation of silica, were not considered due to the high quantities of coagulants demanded by high $\mathrm{Si}$ concentration in leachate solutions. The efficiency of silica removal coupled with efficient phosphorus leaching in minerals acids, mainly $\mathrm{HCl}$ and $\mathrm{HNO}_{3}$, is explored. The kinetics and mechanism of silica precipitation is also discussed.

\section{Experimental section}

\subsection{Materials}

Fly ash (FA) samples originated from wood-based biomass fuel in a circulatory fluidized bed reactor were collected from Alholmens Kraft Oy. A RETSCH sieve shaker (AS200 basic) was employed for dry sieving with sieve size of 125 $\mu \mathrm{m}$ for 30 minutes. $100 \mathrm{~g}$ of FA was taken for screening. Then the fractionated FA (FFA) containing particle size lower than $125 \mu \mathrm{m}$ (59 g) was used for acid leaching, since these fractions contain the major proportion of the phosphorus 
and less silica than the pristine fly ash [11]. Hydrochloric acid $(\geq 37 \%)$ from Honeywell-Fluka and nitric acid $(\geq 65 \%)$ from Sigma-Aldrich were used in the leaching experiments.

\subsection{Leaching experiments}

A high molar acid concentration with lower leaching time is adopted in this study, since the former facilitates $\mathrm{Si}$ precipitation, while a prolonged leaching in low acid concentration would complicate dephosphorization because of phosphorus reprecipitation with other metal ion released during the leaching [25]. $2 \mathrm{M}, 5 \mathrm{M}$ and $8 \mathrm{M}$ solutions of $\mathrm{HCl}$ and $\mathrm{HNO}_{3}$ were prepared for leaching tests of fly ash. Preliminary investigation indicated an optimal liquid to solid (LS) ratio of 12 for a leaching time of 15-20 minutes. Therefore, $20 \mathrm{~g}$ of fractionated fly ash was added to $240 \mathrm{~mL}$ of mineral acid. The leaching process was assisted with mechanical stirring (rate of $500 \mathrm{rpm}$ ) and ultra-sound digestion $(37 \mathrm{kHz}$, at room temperature) for $20 \mathrm{~min}$. The undissolved residues were separated with centrifugation.

\subsection{Silica precipitation experiment}

$\mathrm{pH}$, temperature and ionic strength of the solution are the key parameters that affect the precipitation of Si-gel particles in acidic media [22, 23, 24]. Wilhelm and Kind employed an unstirred setup for investigating the influence of these parameters on the formation of the solid and the resulting gel network to avoid an adiabatic temperature rise due to stirring. Moreover, stirring also causes destruction of the gel network allowing its shrinkage, hinders growth of silica gel polymers and yields smaller Si particles [24, 26]. Therefore, this study adopts unstirred batch precipitation to study the effect of acid concentration and temperature on the formation of Si-gel particles in the context of their removal from the solution. A separate investigation was also carried out to study the effect of stirring on silica removal.

In this study, $10 \mathrm{~mL}$ of each leachate solution obtained after centrifugation were transferred to a $15 \mathrm{~mL}$ centrifuge tube and left for aging of silica gel at 
room temperature and also at 40 and $60^{\circ} \mathrm{C}$ (with an accuracy of $\pm 3^{\circ} \mathrm{C}$ ) in order to examine the influence of temperature. Magnetic stirring was employed for the stirring experiments. Each sample was centrifuged after a certain time interval (0 - $75 \mathrm{~h})$ to separate the silica gel. Centrifugation was used to shrink the volume of polymeric silicic acid gel-network, as the applied "enforced syneresis" in mechanical or external form contribute to shorter shrinkage time [27].

\subsection{Analytical methods}

\subsubsection{Sample characterization}

The elemental composition of fly ash samples was determined with an ICPOES PerkinElmer Optima 8300 instrument. $0.25 \mathrm{~g}$ of FA and FFA were dissolved in $3 \mathrm{~mL}$ of aqua regia with 3-4 drops of hydrofluoric acid. The digestion was further assisted by ultrasound for $18 \mathrm{~min}$ at $60^{\circ} \mathrm{C}$. The samples were shaken in between the digestion to release the evolved gas.

The silica gels were dried and characterized with Zeiss EVO-50XVP Scanning Electron Microscope (SEM) and Bruker Quantax 400 EDS for visual and elemental analysis.

\subsubsection{Measurement of soluble and precipitated silica}

$1 \mathrm{~mL}$ of supernatant was extracted after separation of Si-gel via centrifugation and diluted to $100 \mathrm{~mL}$ to quench further polymerization of Si and precipitation. The concentration of dissolved or soluble silica and other analytes was determined from the quenched fraction with ICP-OES as a function of time. The concentration of precipitated Si-gel at given times was determined by subtraction from the known initial soluble silica concentration in the solution.

\section{Results and discussion}

\subsection{Silica removal during fractionation}

The elemental composition of the pristine FA and FFA determined with ICPOES is presented in Table 1. The advantage of fly ash fractionation was studied and presented in our earlier study [11]; it summarizes that sieving of fly ash can 
Table 1: Major element and heavy metal contents of FA and FFA determined by ultrasound acid digestion followed by ICP-OES measurement.

\begin{tabular}{lllllll|lllllll}
\hline \multirow{2}{*}{ Element } & \multicolumn{3}{l|}{ Major element $(\mathrm{g} / \mathrm{kg})$} & \multicolumn{9}{l}{ Heavy metal $(\mathrm{mg} / \mathrm{kg})$} \\
\cline { 2 - 15 } & $\mathrm{P}$ & $\mathrm{Al}$ & $\mathrm{Fe}$ & $\mathrm{Si}$ & $\mathrm{Mg}$ & $\mathrm{Ca}$ & $\mathrm{Zn}$ & $\mathrm{Cu}$ & $\mathrm{Cr}$ & $\mathrm{Pb}$ & $\mathrm{Ni}$ & $\mathrm{As}$ & $\mathrm{Cd}$ \\
\hline FA & 12.1 & 33.8 & 20 & 173 & 21.6 & 154 & 1704 & 89.6 & 45.1 & 26.3 & 24.6 & 6.7 & 8.6 \\
FFA & 16.7 & 31 & 20.3 & 45.4 & 28.3 & 217.5 & 2595 & 99.7 & 50.4 & 35.2 & 33.7 & 11.7 & 11.5 \\
\hline
\end{tabular}

remove up to $73 \%$ of silicon by discarding $41 w \%$ of fly ash. This fractionation increased the phosphorus content by a factor of 1.38 and the concentration of other matrix elements and heavy metals also increased, as shown in Table 1.

\subsection{Leaching behavior of $\mathrm{P}$, Si and other matrices in $\mathrm{HCl}$ and $\mathrm{HNO}_{3}$}

The mineral acid used and its concentration are the major factors that affect the leaching behavior of phosphorus and other elements [1,2]. Details of the leaching experiments are summarized in Table 2. Phosphorus leaching was more efficient with $\mathrm{HCl}$ than with $\mathrm{HNO}_{3}$, while varying the acid concentration between $2 \mathrm{M}$ and $8 \mathrm{M}$ had only a small effect on the $\mathrm{P}$ leachability. On the other hand, lower concentrations of acid showed the highest Si leachability, the order of leaching feasibility being $2 \mathrm{M}>5 \mathrm{M}>8 \mathrm{M}$ for both $\mathrm{HCl}$ and $\mathrm{HNO}_{3}$. A similar behavior of Si leaching from zeolite analcime and sodium metasilicate nonahydrate $(\mathrm{SMN})$ with $\mathrm{HCl}$ was also reported by Fogler et al. [22]. The low dissolution of silicon in concentrated acid may be attributed to the low availability of $\mathrm{OH}^{-}$groups that assist the formation and stabilization of orthosilicic acid $\left(\mathrm{Si}(\mathrm{OH})_{4}\right)$ in the leachate solution and simultaneous precipitation of silica gel particles.

This study uses acid concentrations higher than the stoichiometric concentration required to dissolve the phosphates from ash residues. In order to attribute the effect of $\mathrm{H}^{+}$ions on Si removal, the remaining $\mathrm{H}^{+}$ion concentration was estimated by Eq.1.

$$
\mathrm{H}_{\text {leachate }}^{+}=\mathrm{H}_{\text {added }}^{+}-1.1 \times(2 \times[\mathrm{Ca}]+2 \times[\mathrm{Mg}]+2 \times[\mathrm{Si}])+3 \times[\mathrm{P}]
$$


Table 2: Concentration of $\mathrm{P}, \mathrm{Si}, \mathrm{Fe}, \mathrm{Al} \mathrm{Mg}$ and $\mathrm{Ca}$ in the leachate solution obtained after leaching and the approximated $\mathrm{H}^{+}$remaining in the leachate.

\begin{tabular}{|c|c|c|c|c|c|c|c|c|}
\hline \multirow{2}{*}{\multicolumn{2}{|c|}{ Acid $(\mathrm{M})$}} & \multicolumn{6}{|c|}{ Concentration $(\mathrm{mg} / \mathrm{L})$} & \multirow{2}{*}{$\begin{array}{c}\mathrm{H}_{\text {leachate }}^{+} \\
(\mathrm{M})\end{array}$} \\
\hline & & $\mathrm{P}$ & $\mathrm{Si}$ & $\mathrm{Fe}$ & $\mathrm{Al}$ & $\mathrm{Mg}$ & $\mathrm{Ca}$ & \\
\hline \multirow{6}{*}{$\mathrm{HCl}$} & \multirow{2}{*}{2} & 1407 & 2403 & 760 & 1346 & 2162 & 18831 & \multirow{2}{*}{0.72} \\
\hline & & $(100.9)$ & $(63.6)$ & $(44.8)$ & $(52.1)$ & $(91.7)$ & $(103.9)$ & \\
\hline & r & 1388 & 2135 & 911 & 1319 & 2097 & 17410 & \multirow{2}{*}{3.82} \\
\hline & 5 & $(99.5)$ & $(56.5)$ & $(53.7)$ & $(51.1)$ & $(88.9)$ & $(96)$ & \\
\hline & \multirow{2}{*}{8} & 1425 & 1947 & 1154 & 1380 & 2181 & 17324 & \multirow{2}{*}{6.84} \\
\hline & & $(102.2)$ & $(51.5)$ & $(68.0)$ & $(53.4)$ & $(92.4)$ & $(95.6)$ & \\
\hline \multirow{6}{*}{$\mathrm{HNO}_{3}$} & \multirow{2}{*}{2} & 1298 & 2472 & 673 & 1343 & 2123 & 18301 & \multirow{2}{*}{0.74} \\
\hline & & $(93.1)$ & $(65.4)$ & $(39.7)$ & $(52)$ & $(90)$ & $(101)$ & \\
\hline & \multirow{2}{*}{5} & 1355 & 2179 & 767 & 1347 & 2100 & 18098 & \multirow{2}{*}{3.78} \\
\hline & & $(97.2)$ & $(57.6)$ & $(45.2)$ & $(52.1)$ & $(89)$ & $(99.8)$ & \\
\hline & \multirow{2}{*}{8} & 1288 & 1811 & 760 & 1234 & 1950 & 16701 & \multirow{2}{*}{6.89} \\
\hline & & $(92.3)$ & $(47.9)$ & $(44.8)$ & $(47.8)$ & $(82.6)$ & $(92.1)$ & \\
\hline
\end{tabular}

* values in ( ) indicates leaching recovery \% 
where $\mathrm{H}_{\text {added }}^{+}$is the molar concentration of acids used during leaching and $[\mathrm{Ca}],[\mathrm{Mg}],[\mathrm{Si}]$ and $[\mathrm{P}]$ are the concentrations $(\mathrm{mol} / \mathrm{L})$ of $\mathrm{Ca}, \mathrm{Mg}, \mathrm{Si}$ and $\mathrm{P}$ in the leachate solution. Factors multiplying the analyte concentration term are the fractions of $\mathrm{H}^{+}$consumed per mole of the analytes during dissolution of the model solid as shown in Eq. 2 - 5. $\mathrm{Ca}, \mathrm{Mg}$ and $\mathrm{Si}$ are the major matrix elements in the leachate solution that consume most of the $\mathrm{H}^{+}$ions during dissolution of the $\mathrm{CaO}, \mathrm{MgO}$ and $\mathrm{NaAlSi}_{2} \mathrm{O}_{6}$ (analcite) as model compounds. It is also assumed that an additional $10 \%$ of $\mathrm{H}^{+}$is consumed by other compounds. Similar strategy was employed to determine the stoichiometric concentration of $\mathrm{H}_{2} \mathrm{SO}_{4}$ required to leach phosphorus from sewage sludge ash (SSA) [28, 29]. The remaining $\mathrm{H}^{+}$in the leachate solutions is also presented in Table 2 .

$$
\begin{gathered}
\mathrm{H}_{3} \mathrm{PO}_{4} \longrightarrow 3 \mathrm{H}^{+}+\mathrm{PO}_{4}{ }^{3-} \quad\left(\left[\mathrm{H}^{+}\right] /[\mathrm{P}]\right)=3 \\
\mathrm{CaO}+2 \mathrm{HCl} \longrightarrow \mathrm{CaCl}_{2}+\mathrm{H}_{2} \mathrm{O} \quad\left(\left[\mathrm{H}^{+}\right] /[\mathrm{Ca}]\right)=2 \\
\mathrm{MgO}+2 \mathrm{HCl} \longrightarrow \mathrm{MgCl}_{2}+\mathrm{H}_{2} \mathrm{O} \quad\left(\left[\mathrm{H}^{+}\right] /[\mathrm{Mg}]\right)=2 \\
\mathrm{NaAlSi}_{2} \mathrm{O}_{6}+4 \mathrm{HCl}+2 \mathrm{H}_{2} \mathrm{O} \longrightarrow 2 \mathrm{Si}(\mathrm{OH})_{4}+\mathrm{AlCl}_{3}+\mathrm{NaCl} \quad\left(\left[\mathrm{H}^{+}\right] /[\mathrm{Si}]\right)=2
\end{gathered}
$$

\subsection{Effects of acid matrix on silica removal}

The disappearance of dissolved silica was followed as a function of time (Figure 1). The consumption of soluble silica, especially in leachate obtained with $5 \mathrm{M}$ acid, exhibits two kinetic regimes; (i) first regime with slow consumption until silica conversion reaches $\approx 10 \%$ and (ii) second regime with rapid depletion of soluble silica. The earlier phase is referred to as induction time/period, while the later is called polymerization or aggregation zone [30, 31, 32]. Noguera et. al. interpreted induction time as the period until the first particles are detected [33]. The length of induction period is dependent on $\mathrm{pH}$, temperature and silicic acid concentration. Higher supersaturation and acidity are also linked with shorter induction times [34]. An inverse relation between the solubility of silica and acid concentration was reported in $\mathrm{HCl}$ and $\mathrm{HNO}_{3}$ matrices [35, 36]. A decrease in solubility of silica is associated with an increase in the supersaturation and thereby promotes the silica precipitation. In addition, the polymerization 


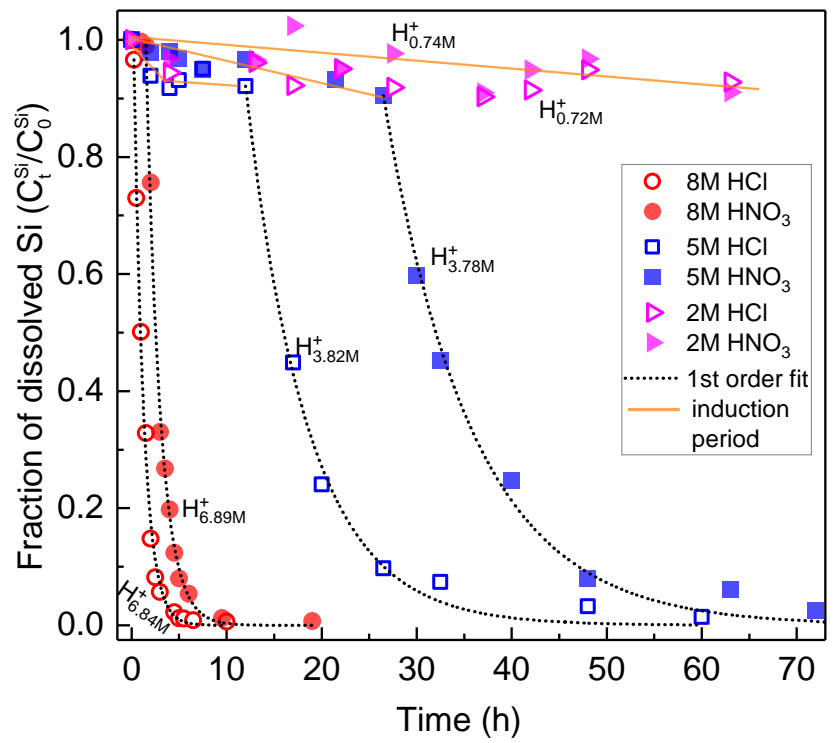

Figure 1: Disappearance of dissolved silica concentration $\left(C_{t}^{S i}\right)$ as a function of time showing the measured data and best fitted modeled data for Si-gelation in acid leached solutions. $C_{0}^{S i}$ is the total dissolved silica at $\mathrm{t}=0 \mathrm{~h}$ and respective concentration are shown in Table 2.

reaction controlling the particle formation and adhesion to initiate gel growth is also charge-catalyzed. Si polymerization below isoelectric point, $\mathrm{pH} 2$ for silicic acid, is catalyzed by $\mathrm{H}^{+}$-ions, while above isoelectric point it is $\mathrm{OH}^{-}$catalyzed $[37,38]$. In this study, shorter induction times and higher Si precipitation rates were observed for leachate solution obtained with high molar concentration of acids. This is attributed to reduced solubility of silica at high concentration of acid and promotion of silica polymerization by $\mathrm{H}^{+}$-ions.

The polymerization process is in a good agreement with a first order kinetic model with respect to the disappearance of dissolved silica. Using the Akaike (AIC) and the Bayesian (BIC) information criteria (Table 3) it was found that the first order had a better fit to the measured data than the second order kinetic models. However, both first order [30,39] and second order [22] consumption of monosilicic acid has been reported in acidic solution.

There is also a clear discrepancy between the leachates obtained with 5 
Table 3: Comparison between $1^{\text {st }}$ and $2^{\text {nd }}$ order kinetic models with respect to the consumption of dissolved silica from the solution.

\begin{tabular}{|c|c|c|c|c|c|c|c|c|c|}
\hline \multirow{3}{*}{ Acid } & \multirow{3}{*}{$(\mathrm{M})$} & \multicolumn{8}{|c|}{ Kinetic model } \\
\hline & & \multicolumn{4}{|c|}{ 1st order } & \multicolumn{4}{|c|}{ 2nd order } \\
\hline & & $-\mathrm{K}$ & $\mathrm{R}^{2}$ & $\mathrm{AIC}$ & $\mathrm{BIC}$ & $-\mathrm{K}$ & $\mathrm{R}^{2}$ & AIC & $\mathrm{BIC}$ \\
\hline \multirow{2}{*}{$\mathrm{HCl}$} & 5 & 0.155 & 0.991 & 34.70 & 31.59 & 0.0014 & 0.982 & 40.22 & 37.11 \\
\hline & 8 & 0.960 & 0.995 & 44.25 & 43.89 & 0.0089 & 0.942 & 74.57 & 74.20 \\
\hline \multirow{2}{*}{ HNO3 } & 5 & 0.107 & 0.992 & 33.95 & 30.84 & 0.0008 & 0.968 & 44.29 & 41.18 \\
\hline & 8 & 0.667 & 0.996 & 35.42 & 34.31 & 0.0063 & 0.945 & 61.68 & 60.57 \\
\hline
\end{tabular}

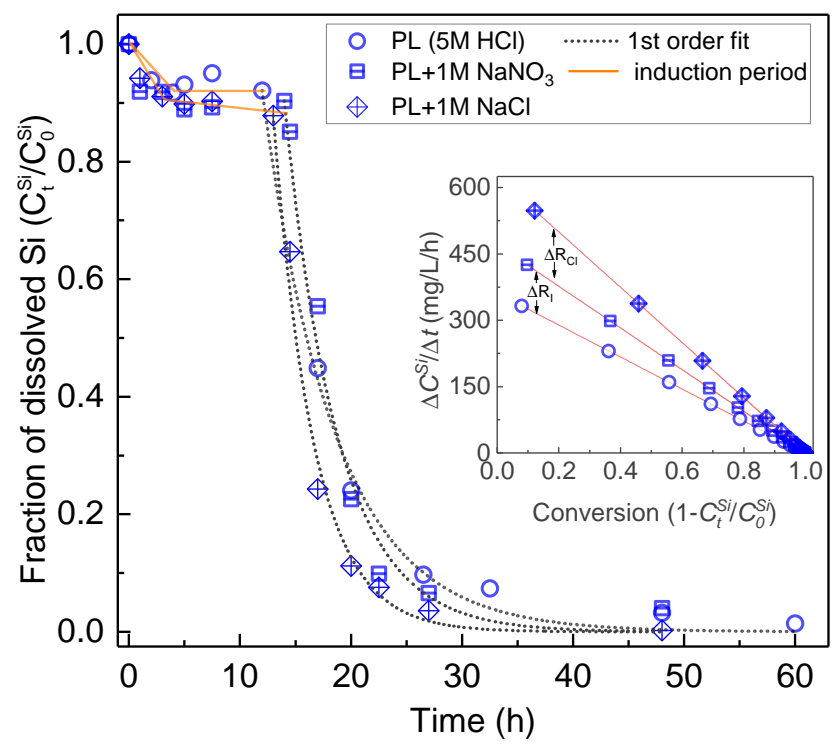

Figure 2: Normalized conversion of dissolved silica vs. time showing increment on silica disappearance rate due to added $\mathrm{Cl}$ in $5 \mathrm{M} \mathrm{HCl}$ pristine leachate (PL) solution, and comparison of instantaneous reaction rate $\left(\Delta \mathrm{C}^{S i} / \Delta \mathrm{t}\right)$ against the conversion of dissolved silica for PL, and leachate with added $1 \mathrm{M}$ of $\mathrm{NaNO}_{3}$ and $\mathrm{NaCl} . \Delta \mathrm{R}_{I}$ indicates the increased Si consumption rate due to increase in ionic strength and $\Delta \mathrm{R}_{C l}$ denotes the increment due to added $\mathrm{Cl}$. $\left(\mathrm{C}_{t}^{S i}\right.$ $=\mathrm{Si}$ concentration at time, $\mathrm{t} ; \mathrm{C}_{0}^{S i}=$ initial dissolved $\mathrm{Si}$ concentration) 
molar concentration of $\mathrm{HCl}$ and $\mathrm{HNO}_{3}$. The approximate $\mathrm{H}^{+}$ion concentrations in these leachates are similar, with respective values of 3.82 and $3.78 \mathrm{M}$. However, these leachates evidently differ in their anion $\left(\mathrm{Cl}^{-}\right.$and $\left.\mathrm{NO}_{3}{ }^{-}\right)$concentrations. Previous studies have reported the catalyzing nature of $\mathrm{F}^{-}$ions in silica polymerization $[24,40]$. In general, anions of single charge, small size, or low polarizability promote the coordination number of silicon(IV) from four to six [41] and reduce the electron density on unsaturated tetravalent Si making it more susceptible to nucleophilic attack from another coordinatively unsaturated Si [40]. This linkage of two monomeric Si species forming a siloxane bond $(\mathrm{Si}-\mathrm{O}-\mathrm{Si})$ is very critical for increasing silica polymer length and particle growth. $\mathrm{Cl}^{-}$ions, sharing the same group in periodic table, possess similar characteristics as $\mathrm{F}^{-}$ions. Therefore, catalysis by $\mathrm{Cl}^{-}$, in the present context, is a possible explanation to the discrepancy between $5 \mathrm{M} \mathrm{HCl}$ and $\mathrm{HNO}_{3}$ acid matrices.

A separate investigation is carried out to examine the catalytic effect of $\mathrm{Cl}^{-}$ ions in the leachate solution obtained from $5 \mathrm{M} \mathrm{HCl}$ acid by addition of $1 \mathrm{M}$ of $\mathrm{NaCl}$ as source of $\mathrm{Cl}^{-}$. In order to differentiate the extent of $\mathrm{Cl}^{-}$catalysis from the influence of increased ionic strength, $1 \mathrm{M}$ of $\mathrm{NaNO}_{3}$ was added in another batch since $1 \mathrm{M}$ of both salts induce equal increases in the ionic strength. In this case, the solution was stirred (magnetic stirring at 400-600 rpm) for only 5 minutes to assist dissolution of salts. Figure 2 shows that addition of $1 \mathrm{M} \mathrm{Cl}^{-}$ ions accelerates the consumption of dissolved silica from the leachate solution by two orders of magnitude. The increment in the instantaneous reaction rate with $1 \mathrm{M} \mathrm{NaNO}_{3}$ is attributed to the increase in ionic strength. Higher salinities $\left(\mathrm{Cl}^{-}\right.$concentration) at $\mathrm{pH} 4.5$ and $95^{\circ} \mathrm{C}$ were found to relate with a higher polymerization rate and shorter induction period [37]. This clearly provides evidence for the results herein. However, a relation between $\mathrm{Cl}^{-}$concentration and the length of induction period was not observed in this study for $1 \mathrm{M}$ of added $\mathrm{Cl}^{-}$ions.

Mechanism of $\mathrm{H}^{+}$and $\mathrm{Cl}^{-}$catalysis for the formation of silica particles and silica gel is presented in Figure 3. It commences with formation of $\mathrm{H}^{+}$and $\mathrm{Cl}^{-}$ 


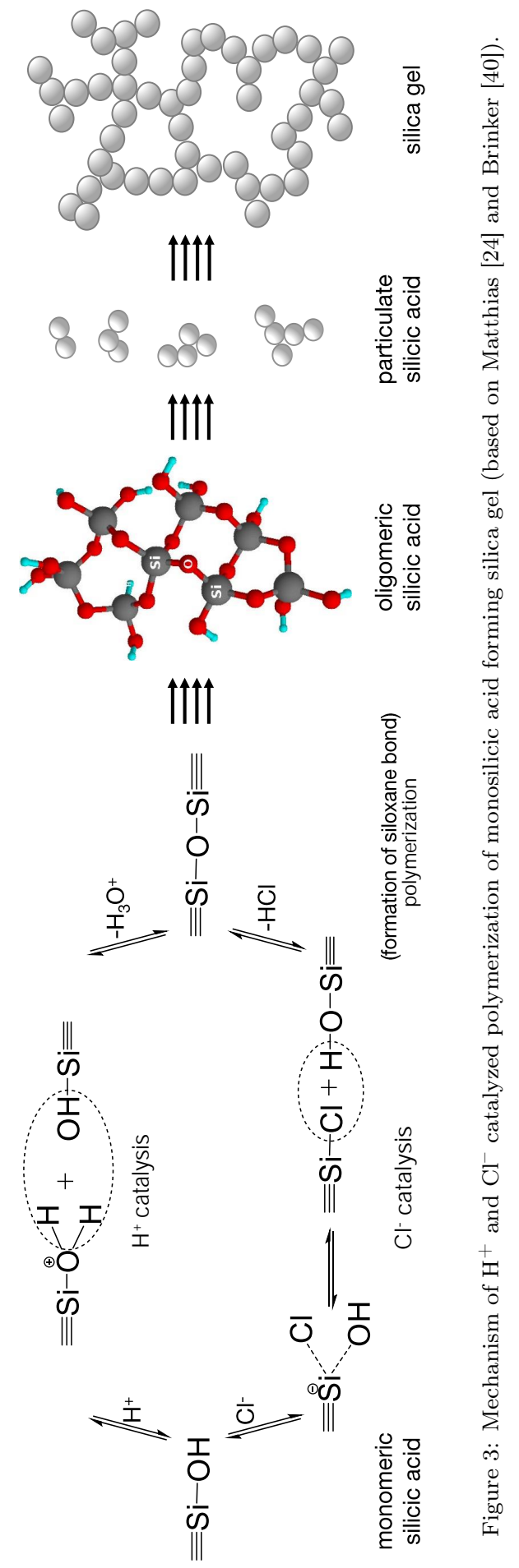


catalyzed siloxane bond where monomeric and dimeric silicic acid polymerizes to yield long oligomers or polymers of silicic acid. These polymeric silica units grow by addition of monomeric silicic acid to yield primary particles $(\sim 20$ $50 \mathrm{~nm}$ ) that aggregate to form particulates of silica followed by gel formation and precipitation [24]. Since gelation is a bonding phenomenon between the aggregates forming particulate network, it is affected by process parameters such as $\mathrm{pH}$, supersaturation, temperature and ions in the solution. Therefore, the removal of silica occurs by formation of Si-gels and precipitation of gel particles by further aggregation.

The total times required to remove $98 \%$ of silicon from the $\mathrm{HCl}$ and $\mathrm{HNO}_{3}$ leachate solutions, were 5 and $10 \mathrm{~h}$ for $8 \mathrm{M}$ concentration, and 48 and $73 \mathrm{~h}$ for 5 M, respectively. Higher $\mathrm{H}^{+}$and $\mathrm{Cl}^{-}$ion concentrations are in a strong relation with shorter induction period and higher Si precipitation rate. Therefore, a high concentration of $\mathrm{HCl}$ acid is identified as suitable reagent in terms of better phosphorus leachability and faster removal of silica from the leachate solution.

\subsection{Effect of temperature on Si precipitation}

The temperature dependence of silica precipitation is examined on leachate obtained with $5 \mathrm{M} \mathrm{HCl}$ solution due to the presence of two kinetic regimes. Figure 4 shows the disappearance of dissolved silica against time at 20, 40 and $60^{\circ} \mathrm{C}$. Increase in temperature significantly reduces the induction time and also increases the silica removal rate. Temperature influences the polymerization of silica by increasing the solubility of monomeric silicic acid and thus affecting its supersaturation [24]. A strong acceleration of silica gelation is in correlation with increasing temperature in the case of acid-catalyzed polymerization [24, 42]. In

addition, the activation energy estimated for silica polymerization in this study for highly acidic leachate solution with $\mathrm{H}^{+}$molar concentration of $3.82 \mathrm{M}$, is ca. $39.25 \mathrm{~kJ} / \mathrm{mol}$. This is also in agreement with the reported activation energy of $37.6 \mathrm{~kJ} / \mathrm{mol}$ for highly acidic gel prepared in $1.65 \mathrm{M}$ of hydrochloric acid [43]. 


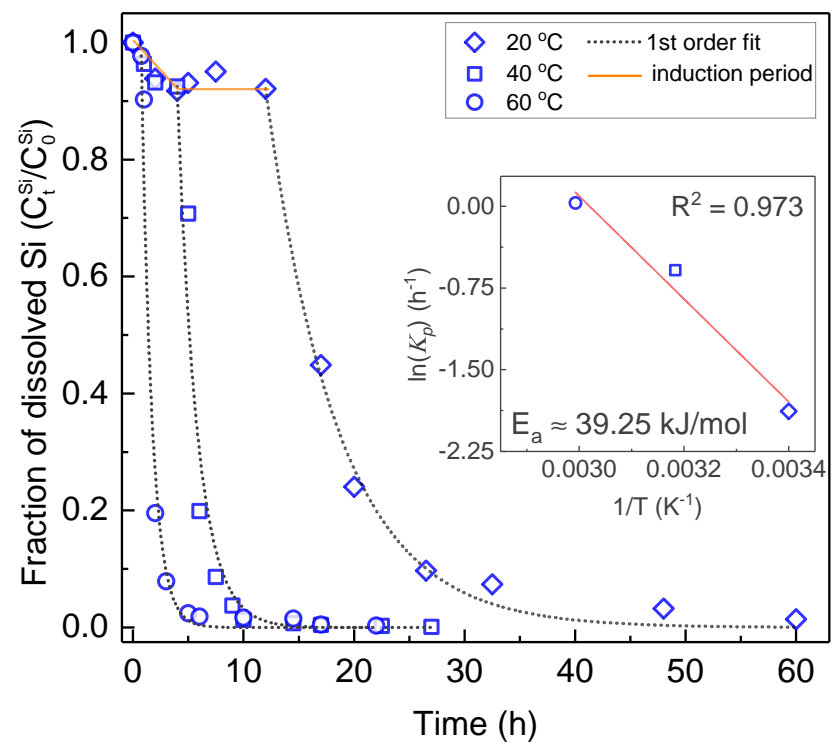

Figure 4: Fraction of dissolved silica in leachate solution as a function of time at various temperatures showing Arrhenius relationship $\left(K_{p}=\mathrm{Ae}^{-E_{a} / R T}\right)$ between the temperature $(\mathrm{T})$ and the first order polymerization reaction constant $\left(K_{p}\right)$ with an activation energy $\left(\mathrm{E}_{a}\right)$ of $39.25 \mathrm{~kJ} / \mathrm{mol}$. 


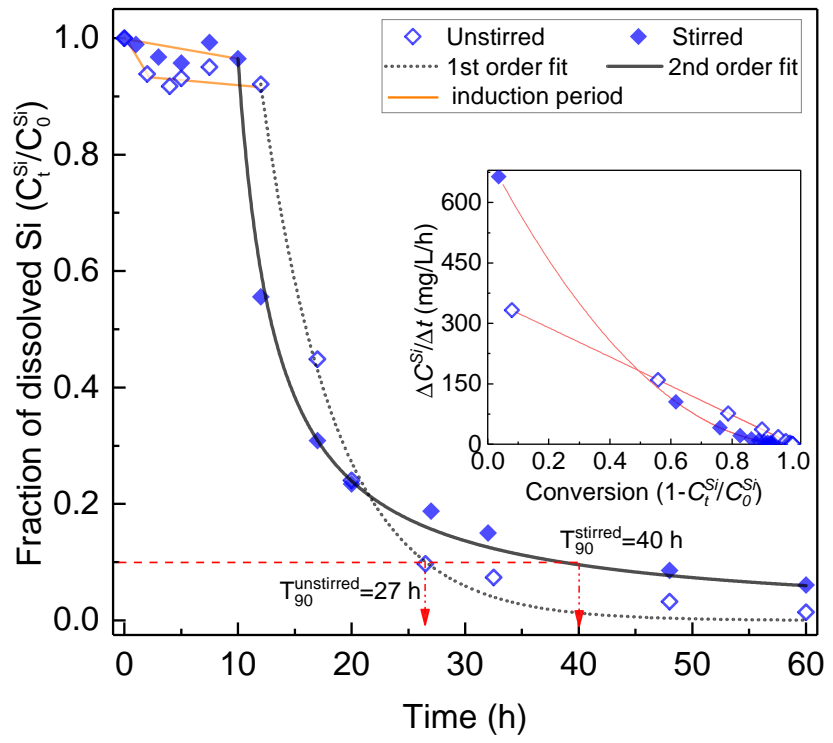

Figure 5: Disappearance of dissolved silica with first and second order consumption in unstirred and stirred batch precipitation showing adverse effect of stirring on polymerization rate $\left(\Delta \mathrm{C}^{S i} / \Delta \mathrm{t}\right)$ after reaching $50 \%$ of conversion and resulting in longer removal time. Time to remove $90 \%$ of silica ( $\mathrm{T}_{90}$ ) from the leachate solutions were 27 and $40 \mathrm{~h}$ for unstirred and stirred case respectively. 


\subsection{Effect of stirring on Si removal}

Stirring or mixing the solution is one of the important parameters in the kinetics of silica polymerization and precipitation [27]. In silica polymerization assisted with coagulants or preparation of silica gel from various silica sources, stirring is employed to improve the dissolution and diffusion of the added reagents. Stirring of the solution increases the dissipation energy during gel formation and results in smaller gel fragments [24]. In addition, effect of stirring on the morphology and particle size distribution of the precipitated silica is also reported [44]. However, this study examines the effects of stirring on $\mathrm{H}^{+}$ and $\mathrm{Cl}^{-}$catalyzed silica polymerization emphasizing the removal of dissolved silica from the pristine leachate solution.

Figure 5 indicates a small reduction in the induction time due to stirring, while a significant deviation in consumption of dissolved silica and reaction kinetics is observed. Second order consumption of dissolved silica in the stirred case shows better agreement with the measured data in contrast to first order consumption under unstirred conditions. In addition, stirring prolongs the silica removal with minimum $40 \mathrm{~h}$ required to remove $90 \%$ of the dissolved silica, while only $27 \mathrm{~h}$ was required in case of unstirred solution. This effect is attributed to either fragmentation of silica gel or hindrance in particle growth due to continuous stirring. In this study, unstirred conditions assist in quick removal of silica from the solution in comparison to the stirred case. However, further investigation is required on the impacts of continuous stirring and stirring only in initial kinetic regimes in the context of silica removal at various mixing rates in highly acidic conditions.

\subsection{Comparison of silica removal rate induced by operational parameters}

A brief comparison of instantaneous silica polymerization rates induced by $\mathrm{H}^{+}, \mathrm{Cl}^{-}$and temperature is shown in Figure 6. In this study, using one variable at a time (OVAT) method, high concentration of $\mathrm{HCl}$ matrix and high temperature are established as important factors that promote silica removal via Si-gelation and precipitation. This study shows that $8 \mathrm{M} \mathrm{HCl}$ leachates 


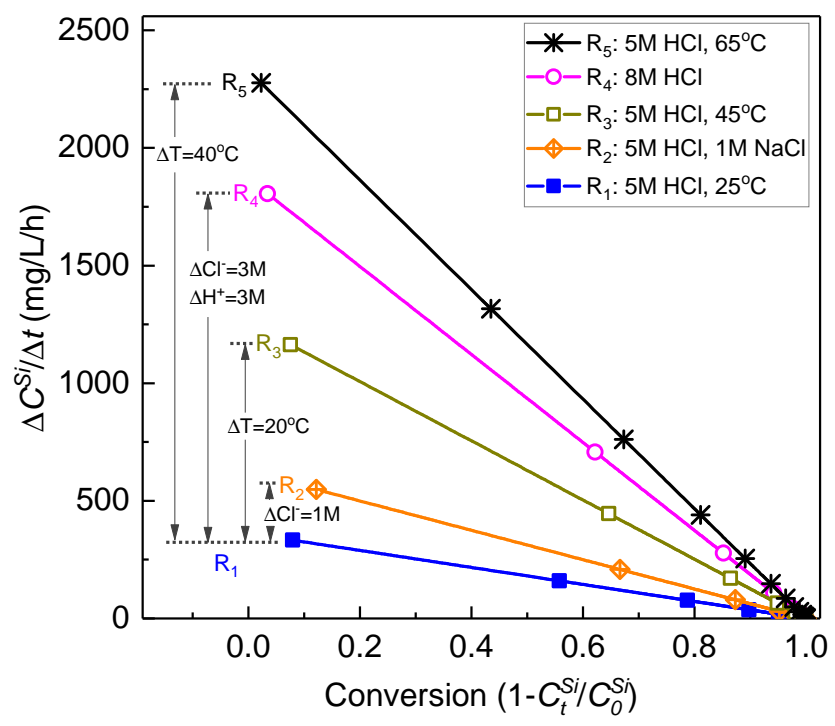

Figure 6: Comparison of $\mathrm{H}^{+}, \mathrm{Cl}^{-}$and temperature induced silica removal rate $\left(\Delta \mathrm{C}^{S i} / \Delta \mathrm{t}\right)$ as a function of normalized silica conversion.

at $20^{\circ} \mathrm{C}$ and $5 \mathrm{M} \mathrm{HCl}$ leachates at $60^{\circ} \mathrm{C}$ prompt $99 \%$ of silica removal in $5 \mathrm{~h}$; concentrations of their analytes before and after Si-removal are listed in Table 4.

Based on the volume of leachate recovered after Si-gelation, the fraction of analytes retained in the gel is estimated with equation;

$$
(\%)=\left(1-v_{f}\left(C_{f} / C_{i}\right)\right) \times 100
$$

where $C_{i}, C_{f}$ are initial and final concentrations of analytes and $v_{f}$ is the fraction of leachate volume recovered after Si-gel separation. The major difference appears in terms of recovered leachate volume; 75 and $87 \%$ of leachate volume were recovered for leachate obtained with $5 \mathrm{M} \mathrm{HCl}$ aged at $60^{\circ} \mathrm{C}$ and $8 \mathrm{M} \mathrm{HCl}$ aged at $20^{\circ} \mathrm{C}$. This difference in the recovered volume is linked with a larger gel volume at higher temperature. The large gel volume is due to a stiffer, stronger gel network [38] and lower tendency of gel shrinkage at higher temperatures for acid-catalysed polymerization [24]. In addition, macroscopic silica particles were not visible in gel at the higher temperature. Due to larger gel volume, 
Table 4: Initial and final (after $5 \mathrm{~h}$ of aging) concentration of major and trace elements for 8 $\mathrm{M} \mathrm{HCl}$ leachate at $20^{\circ} \mathrm{C}$ and $5 \mathrm{M} \mathrm{HCl}$ leachate at $60^{\circ} \mathrm{C}$

\begin{tabular}{|c|c|c|c|c|c|c|}
\hline \multirow{3}{*}{ Element } & \multicolumn{3}{|c|}{$8 \mathrm{M} \mathrm{HCl}$ leachate, $20^{\circ} \mathrm{C}$} & \multicolumn{3}{|c|}{$5 \mathrm{M} \mathrm{HCl}$ leachate, $60^{\circ} \mathrm{C}$} \\
\hline & $\begin{array}{l}\text { Initial } \\
(\mathrm{t}=0)\end{array}$ & $\begin{array}{l}\text { Final } \\
(\mathrm{t}=5 \mathrm{~h})\end{array}$ & $\begin{array}{l}\text { Retained } \\
\text { in Si-gel }\end{array}$ & $\begin{array}{l}\text { Initial } \\
(\mathrm{t}=0)\end{array}$ & $\begin{array}{l}\text { Final } \\
(\mathrm{t}=5 \mathrm{~h})\end{array}$ & $\begin{array}{l}\text { Retained } \\
\text { in Si-gel }\end{array}$ \\
\hline & \multicolumn{2}{|c|}{$(\mathrm{mg} / \mathrm{L})$} & $(\%)^{\otimes}$ & \multicolumn{2}{|c|}{$(\mathrm{mg} / \mathrm{L})$} & $(\%)$ \\
\hline $\mathrm{P}$ & 1450 & 1490 & 10.6 & 1522 & 1509 & 25.6 \\
\hline $\mathrm{Si}$ & 1950 & 21 & 99.1 & 2435 & 8 & 99.8 \\
\hline $\mathrm{Al}$ & 1320 & 1340 & 11.7 & 1355 & 1377 & 23.8 \\
\hline $\mathrm{Fe}$ & 1095 & 1110 & 11.8 & 1038 & 1058 & 23.5 \\
\hline $\mathrm{Mg}$ & 2150 & 2180 & 11.8 & 2453 & 2482 & 24.1 \\
\hline $\mathrm{Ca}$ & 17700 & 17400 & 14.5 & 16191 & 16188 & 25.0 \\
\hline $\mathrm{Zn}$ & 227 & 226 & 13.4 & 195 & 198 & 23.8 \\
\hline $\mathrm{Cu}$ & 7.6 & 7.4 & 15.3 & 7.1 & 7 & 26.1 \\
\hline $\mathrm{Cr}$ & 3.4 & 3.3 & 15.6 & 2.9 & 2.95 & 23.7 \\
\hline $\mathrm{Pb}$ & 3.1 & 3.2 & 10.2 & 2.6 & 2.8 & 19.2 \\
\hline $\mathrm{Ni}$ & 2.5 & 2.3 & 20.0 & 2.3 & 2.4 & 21.7 \\
\hline As & 1.1 & 0.7 & 44.6 & 1 & 0.8 & 40.0 \\
\hline $\mathrm{Cd}$ & 1 & 1 & 13.0 & 0.9 & 1 & 16.7 \\
\hline
\end{tabular}

more analytes are retained in the gel.

\subsection{Morphology of silica gels}

The formation of particulate silica gel in an $8 \mathrm{M} \mathrm{HCl}$ matrix over time is shown in Figure 6(a-b). The development of macroscopic silica particulates can also be noticed in an $\mathrm{HCl}$ leachate solution, as depicted in Figure 6(c). On the contrary, under similar conditions macroscopic silica particles were not observed in $\mathrm{HNO}_{3}$ leachate solutions. An SEM analysis of oven-dried silica gel reveals various structures of primary silica particles that seems to be dependent on acid matrix. Gels derived from $\mathrm{HCl}$ leachate exhibit pointed rod-shaped particulates (Figure 6(d)) that consist of $3.2-5.77 w_{d r y} \%$ of Si (determined with ICP-OES and Bruker Quantax 400 EDS) and $\mathrm{Cl}$ up to $21 \%$ (determined with Bruker 


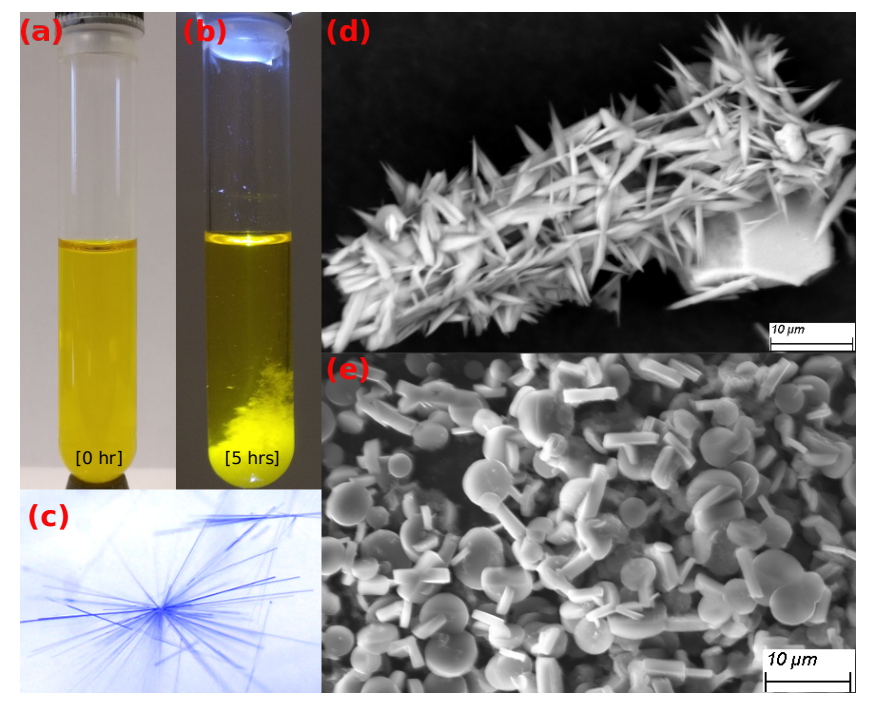

Figure 7: Course of silica gel formation in $\mathrm{HCl}$ leachate solution at 0 hour (a), 5 hours (b), macro image of silica hydrogel (c) and SEM images of dry silica gel particles formed in $\mathrm{HCl}$ matrix (d), and $\mathrm{HNO}_{3}$ matrix (e).

Quantax 400 EDS). On the other hand, gels from $\mathrm{HNO}_{3}$ leachate solution show both spherical and rod-shaped particulates (Figure 6(e)) up to $10 \mu \mathrm{m}$ size and $\mathrm{Si}$ concentration of $2-3.8 w_{d r y} \%$. Minor amounts of $\mathrm{Ca}, \mathrm{Mg}, \mathrm{K}$, and $\mathrm{S}$ were also present. In depth characterization of Si-gels were not performed, since the primary scope of this study was to remove silica from the solution. However, purification, characterization and utilization of silica gels and particles obtained is scheduled for future investigation.

\section{Conclusion}

The aim of this work was to remove silica from CFB-derived fly ash leachate solution with lower chemical and energy demand. This is achieved from a higher molar concentration of acid during leaching process followed by aging of leachate solution. $\mathrm{HCl}$ was more suitable due to its higher phosphorus leaching and silica removal efficiency in comparison with $\mathrm{HNO}_{3}$. The kinetics date demonstrate that the silica removal rate in acid leachate is dependent on the acid concentra- 
tion and temperature. The reaction rate increases significantly as acid concentration increases from $2 \mathrm{M}$ to $8 \mathrm{M}$. Aging of $8 \mathrm{M} \mathrm{HCl}$ leachate for $5 \mathrm{~h}$ reduced the dissolved silica concentration by more than $98 \%$. Moreover, an increase in temperature from 20 to $60^{\circ} \mathrm{C}$ in $5 \mathrm{M} \mathrm{HCl}$ leachate solution decreased the aging time from 48 to $5 \mathrm{~h}$ and also facilitated the removal of $98 \%$ of dissolved silica.

Risks imposed by silica scaling on operational equipment and co-precipitation of colloidal silica during phosphorus precipitation are minimized in silicon-free leachate solutions. Future work will be focused on the selective precipitation of phosphorus from Si-free leachate solution.

\section{Acknowledgements}

The author wishes to thank the Alholmens Kraft heat and power plant for providing fly ash samples.

\section{References}

[1] A. Pettersson, L.-E. Åmand, B.-M. Steenari, Leaching of ashes from co-combustion of sewage sludge and wood-part i: Recovery of phosphorus, Biomass and Bioenergy 32 (3) (2008) 224 - 235. doi:https://doi.org/10.1016/j.biombioe.2007.09.016.

[2] Y. Kalmykova, K. K. Fedje, Phosphorus recovery from municipal solid waste incineration fly ash, Waste Management 33 (6) (2013) 1403 - 1410. doi:https://doi.org/10.1016/j.wasman.2013.01.040.

[3] K. Kaikake, T. Sekito, Y. Dote, Phosphate recovery from phosphorus-rich solution obtained from chicken manure incineration ash, Waste Management 29 (3) (2009) 1084 - 1088. doi:https://doi.org/10.1016/j.wasman.2008.09.008.

[4] M. Lee, D.-J. Kim, Identification of phosphorus forms in sewage sludge ash during acid pre-treatment for phosphorus recovery by chemical fractionation and spectroscopy, Journal of Industrial and Engineering Chemistry 51 (Supplement C) (2017) 64 - 70. doi:https://doi.org/10.1016/j.jiec.2017.02.013. 
[5] P. Thy, B. Jenkins, S. Grundvig, R. Shiraki, C. Lesher, High temperature elemental losses and mineralogical changes in common biomass ashes, Fuel 85 (5) (2006) 783 - 795. doi:https://doi.org/10.1016/j.fuel.2005.08.020.

[6] P. Thy, C. Yu, B. M. Jenkins, C. E. Lesher, Inorganic composition and environmental impact of biomass feedstock, Energy \& Fuels 27 (7) (2013) 3969-3987. doi:10.1021/ef400660u.

URL http://dx.doi.org/10.1021/ef400660u

[7] X. Xiao, H. Yang, H. Zhang, J. Lu, G. Yue, Research on carbon content in fly ash from circulating fluidized bed boilers, Energy \& Fuels 19 (4) (2005) 1520-1525. doi:10.1021/ef049678g.

[8] B.-J. Skrifvars, G. Sfiris, R. Backman, K. Widegren-Dafgård, M. Hupa, Ash behavior in a CFB boiler during combustion of Salix, Energy and Fuels 11 (4) (1997) 843-848. doi:10.1021/ef960208z.

[9] T. Valmari, T. M. Lind, E. I. Kauppinen, G. Sfiris, K. Nilsson, W. Maenhaut, Field study on ash behavior during circulating fluidized-bed combustion of biomass. 1. Ash formation, Energy and Fuels 13 (2) (1999) 379-389. doi:10.1021/ef980085d.

[10] L. S. Johansson, B. Leckner, C. Tullin, L. E. Åmand, K. Davidsson, Properties of particles in the fly ash of a biofuel-fired circulating fluidized bed (CFB) boiler, Energy and Fuels 22 (5) (2008) 3005-3015. doi:10.1021/ef800266c.

[11] R. Budhathoki, A. Väisänen, Particle size based recovery of phosphorus from combined peat and wood fly ash for forest fertilization, Fuel Processing Technology 146 (2016) 85 - 89. doi:http://dx.doi.org/10.1016/j.fuproc.2016.02.016.

[12] S. J. Zarrouk, B. C. Woodhurst, C. Morris, Silica scaling in geothermal heat exchangers and its impact on pressure drop and performance: Wairakei binary plant, new zealand, Geothermics 51 (2014) 445 - 459. doi:https://doi.org/10.1016/j.geothermics.2014.03.005.

URL http://www.sciencedirect.com/science/article/pii/S0375650514000297

[13] L. G. Dyer, W. R. Richmond, P. D. Fawell, Simulation of iron oxide/silica precipitation in the paragoethite process for the removal of iron from acidic 
zinc leach solutions, Hydrometallurgy 119 (Supplement C) (2012) 47 - 54.

doi:https://doi.org/10.1016/j.hydromet.2012.02.017.

[14] S. Bai, G. Naren, M. Nakano, Y. Okaue, T. Yokoyama, Effect of polysilicic acid on the precipitation of calcium carbonate, Colloids and Surfaces A: Physicochemical and Engineering Aspects 445 (Supplement C) (2014) 54 - 58. doi:https://doi.org/10.1016/j.colsurfa.2014.01.008.

[15] D. Hermosilla, R. Ordóñez, L. Blanco, E. de la Fuente, . Blanco, ph and particle structure effects on silica removal by coagulation, Chemical Engineering \& Technology 35 (9) (2012) 1632-1640. doi:10.1002/ceat.201100527.

URL http://dx.doi.org/10.1002/ceat.201100527

[16] Y. Liu, M. Tourbin, S. Lachaize, P. Guiraud, Silica nanoparticle separation from water by aggregation with alcl3, Industrial \& Engineering Chemistry Research 51 (4) (2012) 1853-1863. arXiv:https://doi.org/10.1021/ie200672t, doi:10.1021/ie200672t.

URL https://doi.org/10.1021/ie200672t

[17] D. L. Gallup, F. Sugiaman, V. Capuno, A. Manceau, Laboratory investigation of silica removal from geothermal brines to control silica scaling and produce usable silicates, Applied Geochemistry 18 (10) (2003) 1597 - 1612. doi:https://doi.org/10.1016/S0883-2927(03)00077-5.

URL http: //www.sciencedirect.com/science/article/pii/S0883292703000775

[18] K. Sasan, P. V. Brady, J. L. Krumhansl, T. M. Nenoff, Exceptional selectivity for dissolved silicas in industrial waters using mixed oxides, Journal of Water Process Engineering 20 (2017) 187 - 192. doi:https://doi.org/10.1016/j.jwpe.2017.11.003. URL http: //www.sciencedirect.com/science/article/pii/S2214714417305093

[19] K. Sasan, P. V. Brady, J. L. Krumhansl, T. M. Nenoff, Removal of dissolved silica from industrial waters using inorganic ion exchangers, Journal of Water Process Engineering 17 (2017) 117 - 123. doi:https://doi.org/10.1016/j.jwpe.2017.02.006.

URL http://www. sciencedirect.com/science/article/pii/S2214714416305591

[20] S. Chuang, T. Chang, C. Ouyang, J. Leu, Colloidal silica removal in coagulation processes for wastewater reuse in a high-tech in- 
dustrial park, Water Science and Technology 55 (1-2) (2007) 187195. arXiv:http://wst.iwaponline.com/content/55/1-2/187.full.pdf, doi:10.2166/wst.2007.054.

URL http://wst.iwaponline.com/content/55/1-2/187

[21] S. S. Cob, C. Yeme, B. Hofs, E. Cornelissen, D. Vries, F. G. Güner, G. Witkamp, Towards zero liquid discharge in the presence of silica: Stable 98nanofiltration and reverse osmosis, Separation and Purification Technology 140 (2015) 23 - 31. doi:https://doi.org/10.1016/j.seppur.2014.11.009.

URL http://www.sciencedirect.com/science/article/pii/S1383586614006509

[22] E. A. Gorrepati, P. Wongthahan, S. Raha, H. S. Fogler, Silica precipitation in acidic solutions: Mechanism, pH effect, and salt effect, Langmuir 26 (13) (2010) 10467-10474. doi:10.1021/la904685x.

[23] J. Bałdyga, M. Jasińska, K. Jodko, P. Petelski, Precipitation of amorphous colloidal silica from aqueous solutions - aggregation problem, Chemical Engineering Science 77 (Supplement C) (2012) 207 - 216, 18th International Symposium on Industrial Crystallization. doi:https://doi.org/10.1016/j.ces.2012.03.046.

[24] S. Wilhelm, M. Kind, Influence of $\mathrm{pH}$, temperature and sample size on natural and enforced syneresis of precipitated silica, Polymers 7 (12) (2015) 2504-2521. doi:10.3390/polym7121528.

[25] Y.-s. Jin, T. Jiang, Y.-b. Yang, Q. Li, G.-h. Li, Y.-f. Guo, Removal of phosphorus from iron ores by chemical leaching, Journal of Central South University of Technology 13 (6) (2006) 673-677. doi:10.1007/s11771-006-0003-y.

URL https://doi.org/10.1007/s11771-006-0003-y

[26] S. Wilhelm, M. Kind, Gelation, Fragmentation and Reorganization of Precipitated Silica, Springer International Publishing, 2015, pp. 175-204.

[27] K. Quarch, E. Durand, M. Kind, Inorganic precipitated silica gel. part 2: Fragmentation by mechanical energy, Chemical Engineering \& Technology 33 (7) (2010) 1208-1212. doi:10.1002/ceat.201000081.

URL http://dx.doi.org/10.1002/ceat. 201000081 
[28] S. Donatello, D. Tong, C. Cheeseman, Production of technical grade phosphoric acid from incinerator sewage sludge ash (issa), Waste Management 30 (8) (2010) 1634 - 1642. doi:https://doi.org/10.1016/j.wasman.2010.04.009.

[29] M. Franz, Phosphate fertilizer from sewage sludge ash (ssa), Waste Management 28 (10) (2008) 1809 - 1818. doi:https://doi.org/10.1016/j.wasman.2007.08.011. URL http://www.sciencedirect.com/science/article/pii/S0956053X07002607

[30] R. K. Iler, Isolation and characterization of particle nuclei during the polymerization of silicic acid to colloidal silica, Journal of Colloid And Interface Science 75 (1) (1980) 138-148. doi:10.1016/0021-9797(80)90357-4.

[31] O. Weres, A. Yee, L. Tsao, Kinetics of silica polymerization, Journal of Colloid And Interface Science 84 (2) (1981) 379-402. doi:10.1016/0021-9797(81)90230-7.

[32] H. Rothbaum, A. Rohde, Kinetics of silica polymerization and deposition from dilute solutions between 5 and $180^{\circ} \mathrm{c}$, Journal of Colloid and Interface Science 71 (3) (1979) 533 - 559. doi:https://doi.org/10.1016/0021-9797(79)90328-X.

[33] C. Noguera, B. Fritz, A. Clément, Precipitation mechanism of amorphous silica nanoparticles: A simulation approach, Journal of Colloid and Interface Science 448 (2015) 553 - 563. doi:https://doi.org/10.1016/j.jcis.2015.02.050.

URL http://www.sciencedirect.com/science/article/pii/S0021979715002258

[34] S. Chan, A review on solubility and polymerization of silica, Geothermics 18 (1) (1989) 49 - 56. doi:https://doi.org/10.1016/0375-6505(89)90009-6.

URL http://www.sciencedirect.com/science/article/pii/0375650589900096

[35] V. Lenher, H. B. Merrill, The solubility of silica., Journal of the American Chemical Society 39 (12) (1917) 2630-2638. arXiv:https://doi.org/10.1021/ja02257a013, doi:10.1021/ja02257a013.

URL https://doi.org/10.1021/ja02257a013

[36] T. H. ELMER, M. E. NORDBERG, Solubility of silica in nitric acid solutions, Journal of the American Ceramic Society 41 (12) (1958) 517-520. doi:10.1111/j.1151-2916.1958.tb12907.x. URL http://dx.doi.org/10.1111/j.1151-2916.1958.tb12907.x 
[37] A. C. Makrides, M. Turner, J. Slaughter, Condensation of silica from supersaturated silicic acid solutions, Journal of Colloid and Interface Science 73 (2) (1980) 345 - 367. doi:https://doi.org/10.1016/0021-9797(80)90081-8.

[38] K. Quarch, M. Kind, Inorganic precipitated silica gel. part 1: Gelation kinetics and gel properties, Chemical Engineering \& Technology 33 (6) (2010) 1034-1039. doi:10.1002/ceat.201000080.

URL http://dx.doi.org/10.1002/ceat. 201000080

[39] V. V. Potapov, a. a. Serdan, V. N. Kashpura, V. a. Gorbach, Polycondensation kinetics of orthosilicic acid in a hydrothermal solution, Russian Journal of Physical Chemistry A 81 (10) (2007) 1698-1702. doi:10.1134/S0036024407100287.

[40] C. Brinker, Hydrolysis and condensation of silicates: Effects on structure, Journal of Non-Crystalline Solids 100 (1) (1988) 31 - 50, glasses and Glass Ceramics from Gels. doi:https://doi.org/10.1016/0022-3093(88)90005-1.

[41] A. D. Bishop, J. L. Bear, The thermodynamics and kinetics of the polymerization of silicic acid in dilute aqueous solution, Thermochimica Acta 3 (5) (1972) 399 409. doi:https://doi.org/10.1016/0040-6031(72)87054-0.

[42] C. B. Hurd, Studies on Silicic Acid Gels. VI. Influence of Temperature and Acid upon the Time of Set, The Journal of Physical Chemistry 40 (1) (1935) 21-26. arXiv:https://doi.org/10.1021/j150370a003, doi:10.1021/j150370a003.

URL https://doi.org/10.1021/j150370a003

[43] C. B. Hurd, R. W. Barclay, Studies on Silicic Acid Gels. X. The Time of Set of Gel Mixtures Containing High Concentrations of Mineral Acids, The Journal of Physical Chemistry 44 (7) (1940) 847-851. arXiv:https://doi.org/10.1021/j150403a002, doi:10.1021/j150403a002.

URL https ://doi.org/10.1021/j150403a002

[44] S. Meoto, N. Kent, M. M. Nigra, M.-O. Coppens, Effect of stirring rate on the morphology of fdu-12 mesoporous silica particles, Microporous and Mesoporous Materials 249 (2017) 61 - 66. doi:https://doi.org/10.1016/j.micromeso.2017.04.045. URL http://www. sciencedirect.com/science/article/pii/S1387181117302949 